PÔRTO MLA; PUIATTI M; FONTES PCR; CECON PR; ALVES JC. 2014. Produtividade e acúmulo de nitrato nos frutos da abóbora "Tetsukabuto" em função da adubação nitrogenada. Horticultura Brasileira 32: 280-285. DOI - http://dx.doi.org/10.1590/S0102-05362014000300007

\title{
Produtividade e acúmulo de nitrato nos frutos da abóbora "Tetsukabuto" em função da adubação nitrogenada
}

\author{
Mônica LA Pôrto'; Mário Puiatti²; Paulo CR Fontes²; Paulo R Cecon²; Jailson C Alves' \\ ${ }^{1}$ IFAL, Campus Maragogi, Rod. AL 101 Norte s/n, 57955-000 Maragogi-AL; monicalporto@yahoo.com.br; jailson.alves@ifal.edu.br; \\ 2UFV, Depto. Fitotecnia, 36571-000 Viçosa-MG; mpuiatti@ufv.br; pacerefo@ufv.br; cecon@ufv.br
}

\begin{abstract}
RESUMO
A abóbora híbrida tipo "Tetsukabuto" apresenta crescente importância no Brasil, sobretudo no estado de Minas Gerais mas, poucos estudos têm sido conduzidos em relação à adubação. Assim, o objetivo deste trabalho foi avaliar a produtividade e o acúmulo de nitrato na abóbora híbrida tipo "Tetsukabuto" (cv. Suprema) submetida à adubação nitrogenada. $\mathrm{O}$ experimento foi conduzido no delineamento em blocos casualizados, em esquema fatorial $2 \times 5$, constituído de duas fontes (sulfato de amônio e nitrato de amônio), cinco doses ( 0 ; $50 ; 100 ; 200$ e $400 \mathrm{~kg} \mathrm{ha}^{-1} \mathrm{de}$ N) e quatro repetições. Foram avaliados o número de frutos/planta, massa média de frutos, produtividade da cultura e acúmulo de nitrato nos frutos. Não foram verificados efeitos significativos de fontes e da interação entre fontes e doses de $\mathrm{N}$ sobre as características produtivas, mas essas foram aumentadas em função das doses de $\mathrm{N}$ aplicadas. Os valores de máximo número de frutos/planta (6,9 unidades), máxima massa média de frutos $(1,76 \mathrm{~kg} /$ fruto) e máxima produtividade de frutos $\left(17,16 \mathrm{t} \mathrm{ha}^{-1}\right)$ foram obtidos nas doses 339, 217 e $260 \mathrm{~kg} \mathrm{ha}^{-1}$ de $\mathrm{N}$, respectivamente. As doses de máxima eficiência econômica de $\mathrm{N}$ foram de 251 e $238 \mathrm{~kg} \mathrm{ha}^{-1}$, resultando em produtividades de frutos de 17,15 e 17,07 $\mathrm{t} \mathrm{ha}^{-1}$, para o sulfato de amônio e nitrato de amônio, respectivamente. Não foi verificado aumento do teor de nitrato nos frutos com o emprego das doses de $\mathrm{N}$ na forma de sulfato de amônio. Entretanto, o teor de nitrato nos frutos apresentou incremento linear em função das doses de $\mathrm{N}$ na forma de nitrato de amônio, verificando-se, com a dose máxima, teor de nitrato na matéria fresca de fruto de $406 \mathrm{mg} \mathrm{kg}^{-1}$, valor que não representa risco para a saúde humana.
\end{abstract}

Palavras-chave: Curcubita maxima x C. moschata, Tetsukabuto, nitrogênio, eficiência econômica.

\begin{abstract}
Yield and nitrate accumulation in fruits of hybrid winter squash as a function of the nitrogen fertilization
\end{abstract}

The importance of hybrid winter squash ("Tetsukabuto" type) is rising in Brazil, especially in Minas Gerais state, but few studies have been carried out in relation to fertilization. We evaluated yield and nitrate accumulation in fruits of hybrid winter squash ("Tetsukabuto" type) depending on the nitrogen fertilization in Viçosa, Minas Gerais state, Brazil. The randomized block experimental design was used, arranged in a $2 \times 5$ factorial design, with two nitrogen sources (ammonium sulphate and ammonium nitrate) and five nitrogen doses $\left(0 ; 50 ; 100 ; 200\right.$ and $\left.400 \mathrm{~kg} \mathrm{ha}^{-1}\right)$, and four replications. The number of fruits per plant, average fruit mass, fruit yield and nitrate accumulation in the fruits were evaluated. No significant effects of nitrogen sources and of the interaction between nitrogen sources and nitrogen doses was found on the productive characteristics of the hybrid winter squash, but these characteristics were increased depending on the $\mathrm{N}$ doses applied. The highest number of fruits/plant (6.9 units), highest average fruit mass (1.76 kg/fruit) and highest fruit yield $\left(17.16 \mathrm{t} \mathrm{ha}^{-1}\right)$ were obtained in the doses 339,217 and 260 $\mathrm{kg} \mathrm{ha}^{-1}$ of $\mathrm{N}$, respectively. The rates of $\mathrm{N}$ for maximum economic efficiency were 251 and $238 \mathrm{~kg} \mathrm{ha}^{-1}$, resulting in fruit yields of 17.15 and $17.07 \mathrm{t} \mathrm{ha}^{-1}$, for the ammonium sulfate and ammonium nitrate, respectively. Nitrate accumulation in fruits employing $\mathrm{N}$ doses in the form of ammonium sulfate was not verified. However, the nitrate content in the fruits presented lineal increment depending on the $\mathrm{N}$ doses in the form of ammonium nitrate. At the highest $\mathrm{N}$ rate, the nitrate content in the fruit fresh matter was $406 \mathrm{mg} \mathrm{kg}^{-1}$. However, this nitrate content value does not represent risk for human health.

Keywords: Curcubita maxima x C. moschata, Tetsukabuto, nitrogen, economic efficiency.

(Recebido para publicação em 11 de junho de 2013; aceito em 3 de junho de 2014) (Received on June 11, 2013; accepted on June 3, 2014)

\begin{abstract}
A abóbora híbrida tipo "Tetsukabuto" é um híbrido interespecífico, macho estéril, resultante do cruzamento entre moranga (Cucurbita maxima), como progenitor feminino, com a abóbora (C. moschata), como progenitor masculino (Puiatti \& Silva, 2005). É uma planta anual, em que ocorre o desenvolvimento simultâneo da parte vegetativa, floração e frutificação, com
\end{abstract}

hábito de crescimento indeterminado, podendo as ramas atingirem até $6 \mathrm{~m}$ de comprimento (Filgueira, 2008).

A cultura da abóbora híbrida tipo "Tetsukabuto" possui elevada importância socioeconômica em diferentes regiões do país, onde a produtividade média é de 8-15 t ha-1 (Filgueira, 2008), variando em função da tecnologia aplicada e das características de cada cultivar (Puiatti \& Silva, 2005). Dentre os estados, Minas Gerais, principalmente a região Norte é o maior produtor brasileiro com cerca de $36 \mathrm{mil} \mathrm{t} /$ ano e produtividade média de $15 \mathrm{t} \mathrm{ha}^{-1}$ (Vidigal et al., 2007; Sediyama et al., 2009). Características como rusticidade, precocidade, elevado potencial produtivo, estabilidade de produção, uniformidade no tamanho e coloração do fruto, exce- 
lentes qualidades sensoriais (textura, sabor e reduzido tempo de cozimento) e boa conservação pós-colheita (o que facilita o transporte, a comercialização e a resistência ao armazenamento) justificam a grande aceitação do produto, principalmente, pelos mercados mais exigentes, onde somente os frutos de alta qualidade têm maior preferência (Sediyama et al., 2009).

A adubação nitrogenada é fundamental para a obtenção de adequada produtividade, sendo a dose adequada variável de acordo com a produtividade almejada, cultivar, técnicas de manejo, fonte e condições edafoclimáticas (Pôrto et al., 2012). Apesar da relativa importância econômica e nutricional da abóbora híbrida tipo "Tetsukabuto", poucos estudos têm sido conduzidos sobre adubação, principalmente a nitrogenada. A maioria dos trabalhos sobre adubação aborda apenas outras espécies de cucurbitáceas como melão e melancia.

$\mathrm{O}$ nitrogênio é um nutriente que influencia os processos envolvidos no crescimento e desenvolvimento das plantas, alterando a relação fonte-dreno e, consequentemente, a distribuição de assimilados entre órgãos vegetativos e reprodutivos. Em cucurbitáceas, o aumento da dose de N, até determinado limite, proporciona incremento na área foliar da planta, exercendo efeito na produção de fotoassimilados e, consequentemente, na produção de frutos (Queiroga et al., 2007). Entretanto, a adubação nitrogenada se constitui atualmente em assunto polêmico, pois quando aplicada em excesso pode resultar na redução da qualidade e segurança nutricional devido ao acúmulo de nitrato. $\mathrm{O}$ nitrato, quando ingerido em grandes quantidades, pode causar graves consequências à saúde, como formação de nitrosaminas, substância potencialmente carcinogênica, além da metahemoglobinemia ou sangue azul que reduz o transporte de oxigênio no sangue (Addiscott \& Benjamin, 2004).

Algumas estimativas apontam que as hortaliças correspondem ao grupo de alimentos que mais contribui para a ingestão de nitrato pelo homem, sendo responsáveis por cerca 72 e 94\% da ingestão diária (Turazi et al., 2006). De forma geral, as folhosas como alface, espinafre, repolho, rúcula, entre outras, apresentam tendência para acumular altos teores de nitrato em suas folhas (Beninni et al., 2002; Mantovani et al., 2005; Pôrto et al., 2008), havendo grande interesse em monitorar o teor de nitrato nestas plantas (Beninni et al., 2002). Já hortaliças de flores e frutos, a exemplo da couve-flor e tomate, geralmente mostram tendência de menor acúmulo de nitrato (Santamaria, 2006). Com relação à abóbora híbrida tipo "Tetsukabuto", não há resultados sobre o assunto.

Assim, o presente trabalho teve como objetivo avaliar a produtividade e acúmulo de nitrato nos frutos da abóbora híbrida tipo "Tetsukabuto" em função da adubação nitrogenada.

\section{MATERIAL E MÉTODOS}

$\mathrm{O}$ experimento foi conduzido em área experimental da Universidade Federal de Viçosa, em Viçosa-MG. O solo da área experimental, foi classificado como Argisolo Vermelho-Amarelo Câmbico, textura Argila, com as seguintes características químicas (camada de 0-20 cm): $\mathrm{pH}$ em $\mathrm{H}_{2} \mathrm{O}=5,8$; P-Melhich $=28 \mathrm{mg} \mathrm{dm}^{-3} ; \mathrm{K}=108 \mathrm{mg} \mathrm{dm}^{-3} ; \mathrm{Ca}=3,9$ $\mathrm{cmol}_{\mathrm{c}} \mathrm{dm}^{-3} ; \mathrm{Mg}=0,9 \mathrm{cmol}_{\mathrm{c}} \mathrm{dm}^{-3} ; \mathrm{S}=17$ $\mathrm{mg} \mathrm{dm}{ }^{-3} ; \mathrm{Al}=0 \mathrm{cmol}_{\mathrm{c}} \mathrm{dm}^{-3} ; \mathrm{H}+\mathrm{Al}=$ $5,78 \mathrm{cmol}_{\mathrm{c}} \mathrm{dm}^{-3}$ e matéria orgânica $=$ 3,5 dag $\mathrm{kg}^{-1}$.

As mudas de abóbora híbrida tipo "Tetsukabuto" (cv. Suprema), foram produzidas em bandejas de isopor (72 células), utilizando-se substrato comercial Plantmax $^{\circledR}$. A semeadura foi realizada em 08/03/2010, e as mudas transplantadas para o local de cultivo em 23/03/2010, quando apresentaram duas folhas definitivas.

Utilizou-se o delineamento experimental blocos casualizados, com quatro repetições, duas fontes (sulfato e nitrato de amônio) e cinco doses de N (0; 50; $100 ; 200$ e $400 \mathrm{~kg} \mathrm{ha}^{-1}$ ). A parcela experimental constou de 15 plantas, dispostas em três fileiras com cinco plantas cada, no espaçamento de 3x2 m. Dessas, 11 plantas foram de abóbora híbrida tipo "Tetsukabuto" e quatro plantas foram de abóbora 'Menina brasileira' ( $C$. moschata) (plantas polinizadoras). A área útil da parcela foi constituída das três plantas centrais da fileira central.

A adubação com $\mathrm{P}, \mathrm{K}$ e micronutrientes foi efetuada em função dos resultados da análise química do solo (Casali, 1999). Foram aplicados os equivalentes a $400 \mathrm{~kg} \mathrm{ha}^{-1}$ de superfosfato simples, $50 \mathrm{~kg} \mathrm{ha}^{-1}$ de $\mathrm{KCl}, 15 \mathrm{~kg} \mathrm{ha}^{-1}$ de sulfato de zinco, $10 \mathrm{~kg} \mathrm{ha}^{-1}$ de bórax, $10 \mathrm{~kg} \mathrm{ha}^{-1}$ de sulfato de cobre e $0,5 \mathrm{~kg}$ $\mathrm{ha}^{-1}$ de molibdato de amônio. O sulfato de amônio foi empregado como uma das fontes de $\mathrm{N}$ em razão de essa ser a principal fonte de adubo nitrogenado empregada na cultura. A alta disponibilidade de S no solo (Alvarez et al., 1999) e a aplicação de, aproximadamente, 50 $\mathrm{kg} \mathrm{ha}^{-1}$ desse nutriente como elemento acompanhante do superfosfato simples, sulfato de zinco e sulfato de cobre são suficientes para eliminar possíveis interferências do $\mathrm{S}$ adicionado mediante a aplicação das doses crescentes de $\mathrm{N}$ na forma de sulfato de amônio.

Aos 10 dias antes do transplante das mudas foram aplicados os micronutrientes, $\mathrm{P}, 30 \%$ do $\mathrm{N}$ e $40 \%$ do K. O restante do $\mathrm{N}$ e do $\mathrm{K}$ foi aplicado em duas coberturas, sendo a primeira aos 15 dias após o transplante e a segunda, 25 dias após a primeira (Puiatti \& Silva, 2005).

Foi utilizado o sistema de plantio direto, com abertura de covas com dimensões de 40x40×25 cm para colocação e incorporação do adubo de plantio. Durante a condução da cultura foram realizadas capinas manuais, irrigação por aspersão e controle fitossanitário.

A colheita foi realizada no dia $25 / 06 / 2010$, quando os frutos se apresentavam completamente maduros. $\mathrm{O}$ número de frutos/planta foi obtido pela contagem de todos os frutos colhidos divididos pelo número de plantas, em cada tratamento. A massa média de frutos correspondeu à produção total de frutos dividido pelo número de frutos colhidos, em cada tratamento. Foi determinada também a produção de frutos por parcela e estimada a produtividade em $\mathrm{kg} \mathrm{ha}^{-1}$.

Para determinação do teor de nitrato nos frutos foram empregadas amostras de frutos colhidos no pico produtivo da cultura. Os frutos com tamanho comercial foram coletados, lavados em água de torneira e, posteriormente, em água deionizada. Os frutos foram seccionados 
em cubos, pesados e colocados para secar em estufa de circulação forçada de ar a $75^{\circ} \mathrm{C}$, até atingirem peso constante. Posteriormente, amostras secas de fruto foram trituradas em moinho tipo Willey e tamisadas em peneira de 20 mesh. Na matéria seca dos frutos, após a extração com água em banho-maria a $45^{\circ} \mathrm{C}$, durante uma hora, determinaram-se as concentrações de $\mathrm{N}-\mathrm{NO}_{3}{ }^{-}$por colorimetria, em espectrofotômetro a $410 \mathrm{~nm}$ (Cataldo et al., 1975). Com base nos teores de matéria seca e fresca dos frutos, os teores de nitrato na matéria seca foram convertidos para teores na matéria fresca.

Os resultados obtidos foram submetidos à análise de variância, com desdobramento do efeito quantitativo das doses de $\mathrm{N}$ em regressão, considerando-se até $5 \%$ de probabilidade, utilizando o software SAEG, v. 9.1 (SAEG, 2007). A escolha do modelo, além da significância do ajuste do $\mathrm{R}^{2}$, levou em consideração a explicação biológica do fenômeno em estudo.

As doses de máxima eficiência econômica de $\mathrm{N}$, para cada fonte de $\mathrm{N}$ (sulfato de amônio e nitrato de amônio), foram calculadas igualando-se a derivada primeira da equação de regressão referente à produtividade de frutos de abóbora híbrida tipo "Tetsukabuto" em função das doses de $\mathrm{N}$ à relação entre preços do insumo ( $\mathrm{R} \$ / \mathrm{kg}$ de $\mathrm{N})$ e do produto $(\mathrm{R} \$ / \mathrm{kg}$ de frutos de abóbora híbrida tipo "Tetsukabuto") (Raij, 2011). Foram considerados no cálculo os preços médios de comercialização do insumo e do produto empregados no estado de Minas Gerais, no ano de condução do experimento (2010), que foram de $\mathrm{R} \$$ $3,00 / \mathrm{kg}$ de $\mathrm{N}$ e $\mathrm{R} \$ 7,80 / \mathrm{kg}$ de $\mathrm{N}$, para o sulfato de amônio e nitrato de amônio, respectivamente (CONAB, 2011), e R\$ $0,85 / \mathrm{kg}$ de frutos (preço médio de frutos de abóbora híbrida tipo "Tetsukabuto", considerando o valor médio de comercialização nas seis unidades da CEASA-MG), (CEASA-MG, 2011).

No presente trabalho, a fórmula obtida para a determinação das doses de máxima eficiência econômica de $\mathrm{N}$, para as duas fontes do nutriente empregadas, foi:

Dose de $N=\frac{(110,92-Y)}{2 \times 0,2139}$
Onde: Y é a relação entre os preços do insumo e do produto.

\section{RESULTADOS E DISCUSSÃO}

Não foram verificados efeitos significativos de fontes e da interação entre fontes e doses de $\mathrm{N}$ sobre as características produtivas da abóbora híbrida tipo "Tetsukabuto". Isso demonstra que ambas as fontes de $\mathrm{N}$ empregadas (sulfato de amônio e nitrato de amônio) apresentam eficiência agronômica similar para a produção dessa cultura. Assim, o elevado custo do nitrato de amônio (maior custo/kg de $\mathrm{N}$ ), bem como a dificuldade de aquisição desse produto, torna sua utilização pouco viável do ponto de vista prático como fonte de $\mathrm{N}$ para a produção da cultura da abóbora híbrida tipo "Tetsukabuto", em relação ao sulfato de amônio. Entretanto, foi verificada influência significativa $(\mathrm{p}<0,01)$ das doses de $\mathrm{N}$ sobre todas as características produtivas avaliadas (Figuras 1; 2 e 3), demonstrando que essa cultura é bastante responsiva à adubação nitrogenada.

Os valores das características número de frutos/planta, massa média e produtividade de frutos em função do incremento das doses de $\mathrm{N}$, ajustaram- -se ao modelo quadrático (Figuras 1, 2 e 3). O número máximo de frutos/ planta foi 6,9 unidades, obtido com a dose estimada de $339 \mathrm{~kg} \mathrm{ha}^{-1}$ de N. Esse resultado corresponde a um incremento de 2,4 vezes em relação à testemunha.

Quanto à massa média de frutos (Figura 2), a dose estimada de $217 \mathrm{~kg}$ $\mathrm{ha}^{-1}$ de $\mathrm{N}$ foi responsável pela máxima massa média de frutos (1,76 kg/fruto), correspondendo a um incremento de 1,55 vezes em relação à testemunha.

A máxima produtividade de frutos de abóbora híbrida tipo "Tetsukabuto" $\left(17,16 \mathrm{t} \mathrm{ha}^{-1}\right)$ foi obtida com a dose estimada de $260 \mathrm{~kg} \mathrm{ha}^{-1}$ de $\mathrm{N}$ (Figura $3)$. Esse resultado corresponde a um incremento de 5,2 vezes, em relação à testemunha.

$\mathrm{O} \mathrm{N}$ influencia processos envolvidos no crescimento e desenvolvimento das plantas, alterando as relações fonte-dreno e, consequentemente, a distribuição de assimilados entre órgãos vegetativos e reprodutivos. Em cucurbitáceas, o aumento da dose de $\mathrm{N}$, até determinado limite, proporciona incremento na área foliar da planta, exercendo efeito na produção de fotoassimilados e, consequentemente, na produção de frutos (Queiroga et al., 2007). Os resultados deste trabalho indicam que o efeito da

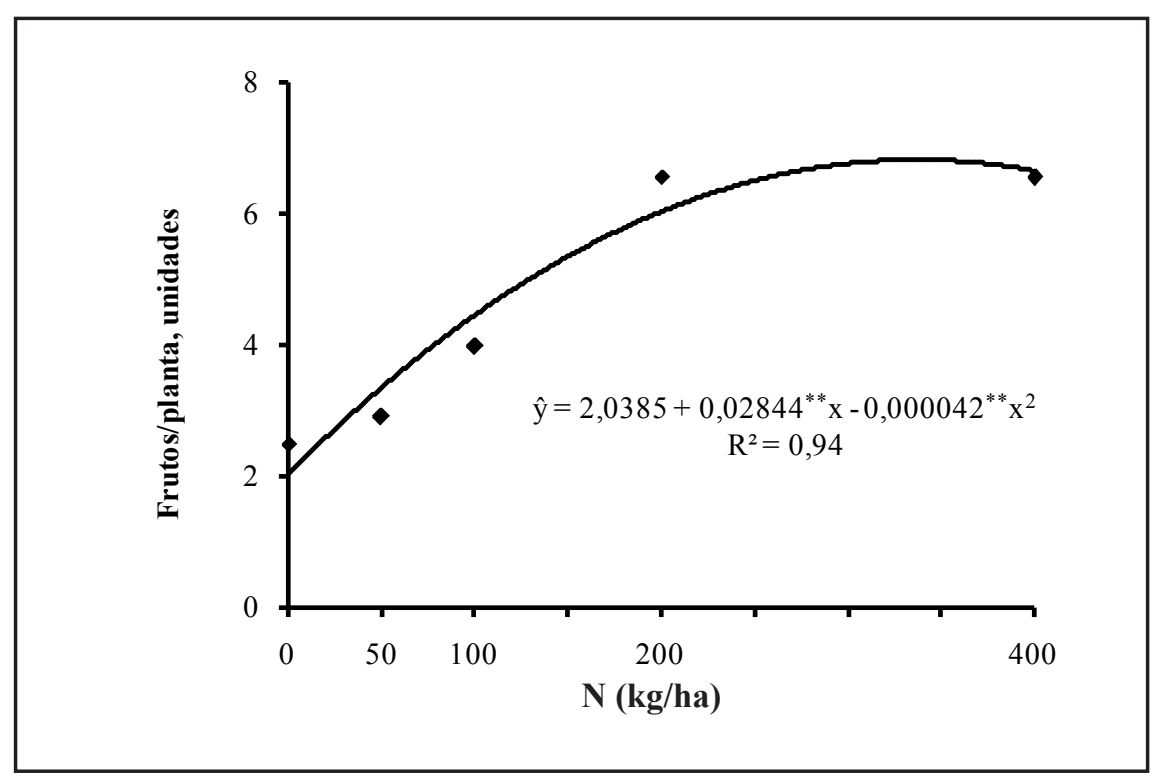

Figura 1. Número de frutos/planta de abóbora híbrida tipo "Tetsukabuto" em função da adubação nitrogenada [number of fruit/plant of hybrid winter squash ("Tetsukabuto" type) depending on the nitrogen fertilization]. Viçosa, UFV, 2010.

${ }^{* *}$ Significativo a $1 \%$ de probabilidade, pelo teste $\mathrm{t}$ (significant at $1 \%$ of probability, $\mathrm{t}$ test). 


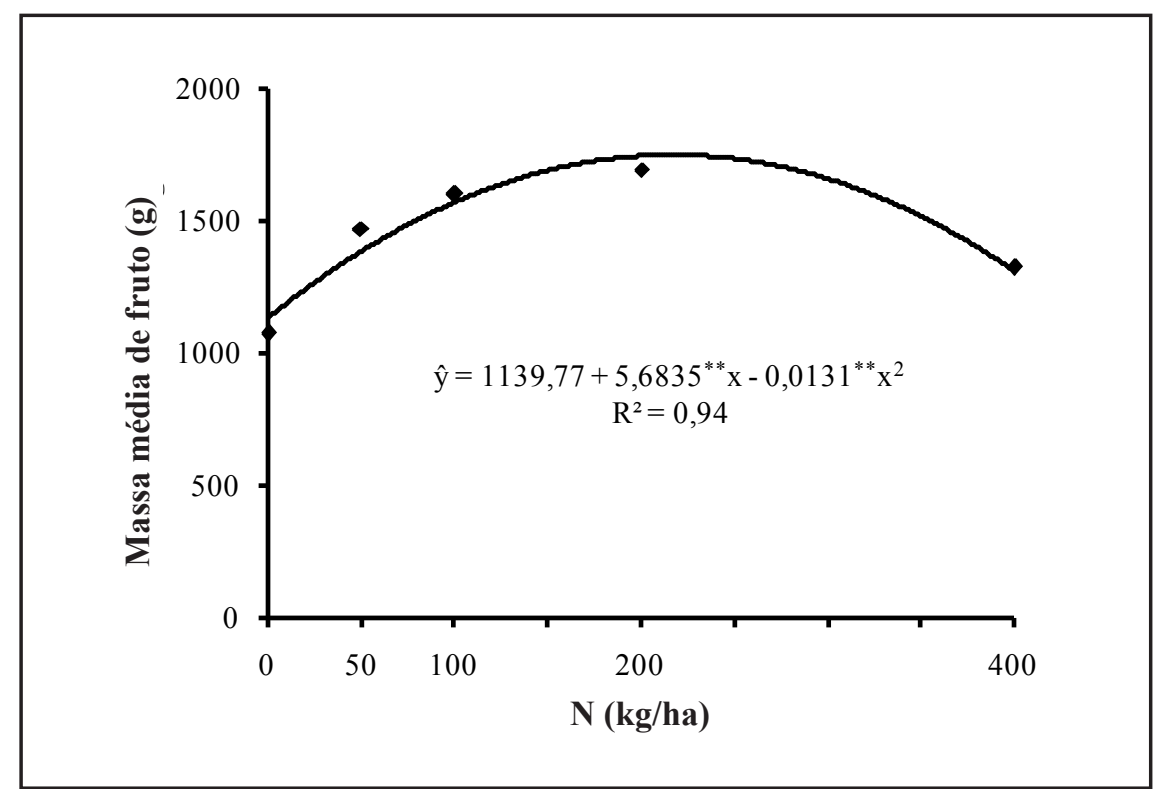

Figura 2. Massa média de fruto de abóbora híbrida tipo "Tetsukabuto" em função da adubação nitrogenada [average fruit mass of hybrid winter squash ("Tetsukabuto" type) depending on the nitrogen fertilization]. Viçosa, UFV, 2010.

${ }^{* *}$ Significativo a $1 \%$ de probabilidade, pelo teste $t$ (significant at $1 \%$ of probability, $t$ test).

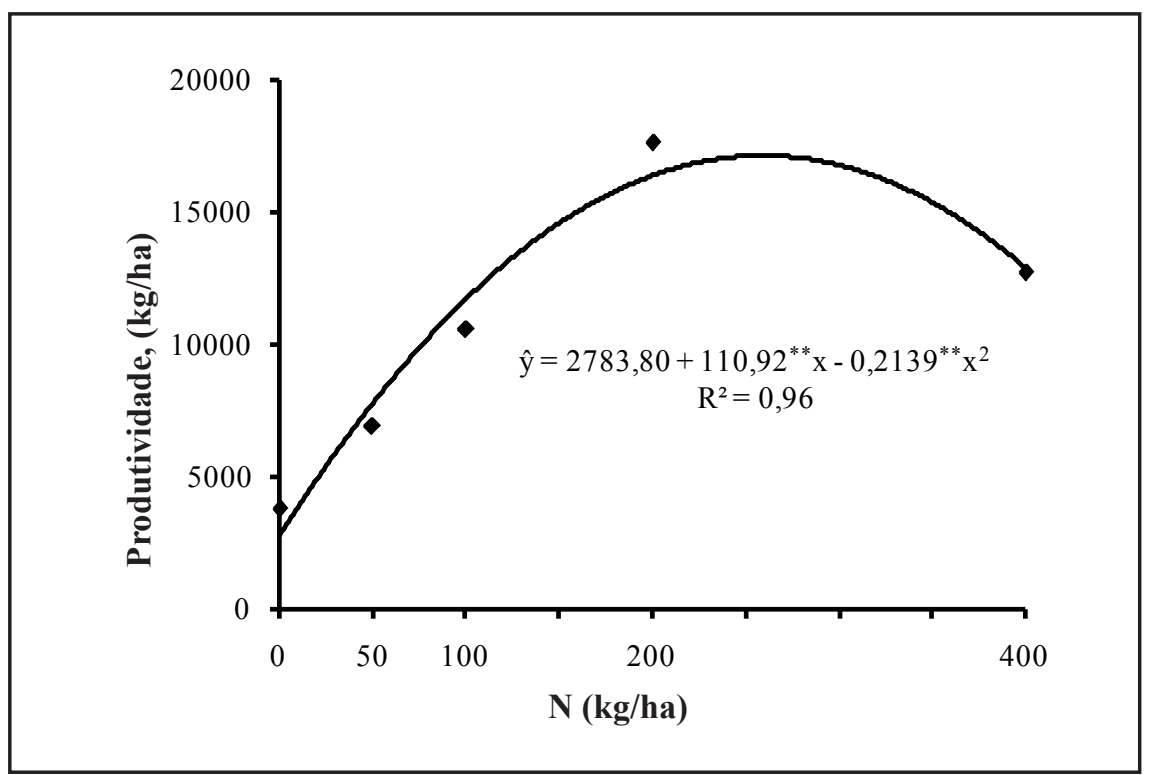

Figura 3. Produtividade de frutos de abóbora híbrida tipo "Tetsukabuto" em função da adubação nitrogenada [yield of hybrid winter squash ("Tetsukabuto" type) fruits depending on the nitrogen fertilization]. Viçosa, UFV, 2010.

${ }^{* *}$ Significativo a $1 \%$ de probabilidade, pelo teste $t$ (Significant at $1 \%$ of probability, $t$ test).

adubação nitrogenada na produção da abóbora híbrida tipo "Tetsukabuto" é resultado do aumento do número e da massa de frutos, que são características determinantes na produtividade da cultura. Em outras cucurbitáceas, como o melão (Queiroga et al., 2007), melancia (Andrade Junior et al., 2006), maxixe
2008), bem como a produtividade média da cultura no estado de Minas Gerais, que é de 15 tha $^{-1}$ (Sediyama et al., 2009). Em cultivo da abóbora híbrida tipo "Tetsukabuto" na região Norte de Minas Gerais, Vidigal et al. (2003) obtiveram produtividade média de frutos de $15,74 \mathrm{tha}^{-1}$, produtividade inferior à obtida no presente trabalho. Avaliando o efeito de doses crescente de $\mathrm{N}(0$ a 150 $\mathrm{kg} \mathrm{ha}^{-1}$ ) sobre a produtividade da abóbora híbrida tipo "Tetsukabuto" no Sudoeste da Bahia, Santos et al. (2010) também constataram efeito positivo das doses de $\mathrm{N}$ sobre a produtividade da cultura. Os referidos autores verificaram efeito linear das doses estudadas sobre a produtividade da cultura, indicando resposta da abóbora híbrida em doses superiores a $150 \mathrm{~kg} \mathrm{ha}^{-1}$, como verificado no presente trabalho.

Para o cultivo da abóbora híbrida no estado de Minas Gerais é recomendado o emprego da dose de $60 \mathrm{~kg} \mathrm{ha}^{-1}$ de $\mathrm{N}$ para uma produtividade de frutos esperada de $12,0 \mathrm{t} \mathrm{ha}^{-1}$ (Casali, 1999). No presente trabalho, com a dose de $\mathrm{N}$ recomendada em MG, a produtividade estimada seria de apenas 8,67 tha ${ }^{-1}$. Esse valor é 50,5\% da máxima produtividade obtida no presente estudo. Portanto, nas condições em que esse trabalho foi realizado, os resultados obtidos sugerem que seria possível alcançar maior produtividade da abóbora híbrida tipo "Tetsukabuto" com dose maior de $\mathrm{N}$ que a recomendada para Minas Gerais, permitindo melhor exploração do potencial produtivo da cultura. Entretanto, mais estudos devem ser feitos em mais estações do ano e tipos de solo antes de alterar a adubação nitrogenada recomendada.

Atualmente, a sustentabilidade é o grande desafio da produção agrícola, sendo que a otimização dos fatores de produção é de fundamental importância para alcançar a produção sustentável, principalmente no que se refere ao uso de fertilizantes. Diante desse aspecto é interessante mensurar a dose de máxima eficiência econômica dos fertilizantes. As doses de máxima eficiência econômica de $\mathrm{N}$ para a produtividade da cultura da abóbora híbrida, empregando como fonte o sulfato de amônio, foi $251 \mathrm{~kg} \mathrm{ha}^{-1}$, para $\mathrm{Y}=3,0$, com produtividade de frutos de $17,15 \mathrm{t} \mathrm{ha}^{-1}$ (incremento de 5,16 vezes em relação à testemunha), e empregando como fonte o nitrato de amônio, foi 238 


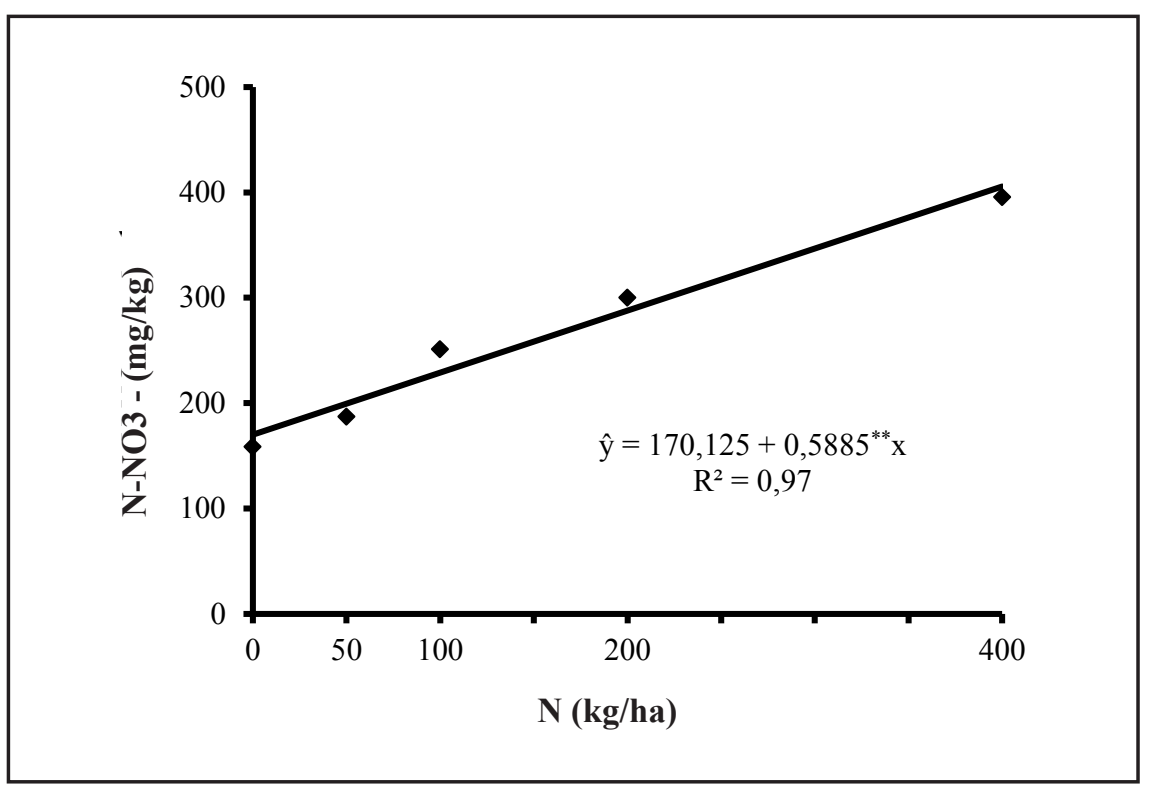

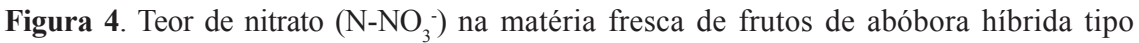
"Tetsukabuto" em função de doses de $\mathrm{N}$ na forma de nitrato de amônio [nitrate $\left(\mathrm{N}^{-} \mathrm{NO}_{3}^{-}\right)$ content in hybrid winter squash ("Tetsukabuto" type) fruits fresh matter depending on the N rates in the form of ammonium nitrate]. Viçosa, UFV, 2010.

${ }^{* *}$ Significativo a $1 \%$ de probabilidade, pelo teste $t$ (significant at $1 \%$ of probability, $t$ test).

$\mathrm{kg} \mathrm{ha}^{-1}$, para $\mathrm{Y}=9,2$, com produtividade de frutos de 17,07 $\mathrm{t} \mathrm{ha}^{-1}$ (incremento de 5,13 vezes em relação à testemunha). As doses de máxima eficiência econômica de $\mathrm{N}$, empregando as duas fontes de $\mathrm{N}$, foram próximas daquela responsável pela máxima produtividade de frutos de abobrinha (97 e $92 \%$ da mesma, empregando como fonte o sulfato de amônio e o nitrato de amônio, respectivamente), indicando que a cultura da abóbora híbrida apresenta elevada resposta em termos econômicos ao emprego de $\mathrm{N}$.

Não foi verificado aumento do teor de nitrato nos frutos de abóbora híbrida com o emprego das doses de $\mathrm{N}$ na forma de sulfato de amônio. Todavia foi verificado acúmulo de nitrato nos tratamentos em que foi empregado como fonte de $\mathrm{N}$ o nitrato de amônio. $\mathrm{O}$ menor acúmulo de nitrato resultante da aplicação de $\mathrm{N}$ na forma amoniacal decorre do fato do amônio se constituir em uma forma rapidamente incorporada em estruturas orgânicas pelas plantas (aminoácidos), enquanto o nitrato deve primeiramente ser reduzido a amônio para posteriormente ser assimilado (Turan \& Sevimli, 2005).

O teor de nitrato nos frutos de abóbora híbrida apresentou incremento linear em função das doses crescentes de $\mathrm{N}$ na forma de nitrato de amônio, verificando- -se na dose máxima aplicada, teor de $406 \mathrm{mg} \mathrm{kg}^{-1}$ de nitrato na matéria fresca (Figura 4). Esse resultado corresponde, em relação à testemunha, um incremento de aproximadamente duas vezes. Considerando a dose de $\mathrm{N}$ recomendada para o cultivo da abóbora híbrida tipo "Tetsukabuto" no estado de Minas Gerais (60 $\left.\mathrm{kg} \mathrm{ha}^{-1} \mathrm{de} \mathrm{N}\right)$ (Casali, 1999), essa dose seria responsável por um teor de $205 \mathrm{mg} \mathrm{kg}^{-1}$ de nitrato na matéria fresca dos frutos de abóbora híbrida. Esses resultados corroboram com o preconizado por Santamaria (2006), que afirma que a abóbora é uma cultura com baixa tendência para acumular nitrato, apresentando teores médios de nitrato na matéria fresca dos frutos variando de 200 a $500 \mathrm{mg} \mathrm{kg}^{-1}$.

Incremento no teor de nitrato em função da aplicação de doses de $\mathrm{N}$ tem sido preconizado na literatura para diferentes hortaliças, como repolho, espinafre (Chen et al., 2004), alface (Pôrto et al., 2008), tomate (Ferreira et al., 2006), abobrinha (Pôrto et al., 2012), dentre outras. O acúmulo de nitrato pelas plantas ocorre quando há excesso de absorção de nitrogênio em relação à capacidade de assimilação deste nutriente, uma vez que, havendo $\mathrm{N}$ disponível no sistema para absorção, a planta tende a absorvê-lo além de sua demanda e estocá-lo nos vacúolos na forma de nitrato (Marschner, 1995).

Os resultados obtidos nesse trabalho demonstram que a fonte de $\mathrm{N}$ empregada exerce influência marcante sobre o acúmulo de nitrato nos frutos de abóbora híbrida tipo "Tetsukabuto", de tal forma que o emprego de $\mathrm{N}$ na forma nítrica, mesmo que parcial, tende a induzir maior acúmulo de nitrato. Todavia, apesar do acúmulo de nitrato observado, o máximo teor de nitrato em frutos de abóbora híbrida obtido é inferior aos preconizados na literatura para outras hortaliças, principalmente folhosas como alface, repolho, espinafre, rúcula, chicória, dentre outras.

Diversos trabalhos têm mostrado que hortaliças folhosas apresentam tendência para acumular altos teores de nitratos em suas folhas (Beninni et al., 2002; Chen et al., 2004; Mantovani et al., 2005; Santamaria, 2006; Pôrto et al., 2008), enquanto que hortaliças de flores e frutos geralmente mostram uma tendência de menor acúmulo de nitrato (Santamaria, 2006). As razões estariam ligadas ao fato do $\mathrm{N}$, ao ascender no caule via corrente xilemática, é dirigido, preferencialmente, às parte da planta com maior taxa transpiratória que são as folhas, justificando o fato de que as hortaliças folhosas tendem a apresentar maior risco de acumular elevados teores de nitrato (Krohn et al., 2003).

A Organização das Nações Unidas para Agricultura e Alimentação (FAO) e a Organização Mundial da Saúde (OMS) estabeleceram o limite de ingestão diária aceitável de nitrato pelo homem de 3,7 $\mathrm{mg} \mathrm{kg}^{-1}$ de massa corporal (WHO, 1995). Considerando esse limite, e partindo do maior teor de nitrato obtido nos frutos, de forma a desprezar a contribuição das demais fontes de nitrato para o homem, verifica-se que uma pessoa com $70 \mathrm{~kg}$ de massa corporal poderia consumir, diariamente, até $630 \mathrm{~g}$ de frutos de abóbora híbrida tipo "Tetsukabuto". Portanto, essa quantidade está bastante acima das estimativas de consumo de uma pessoa normal com essa condição corporal, demonstrando que o valor obtido na maior dose de $\mathrm{N}$ utilizada não forneceria risco à saúde humana.

Os resultados obtidos sugerem que é possível alcançar maior produtividade de frutos na cultura da abóbora híbrida 
tipo "Tetsukabuto" com a aplicação de maior dose de $\mathrm{N}$ do que a recomendada para Minas Gerais, permitindo melhor exploração do potencial produtivo da cultura. A dose de máxima eficiência econômica de $\mathrm{N}$ para a produtividade da cultura da abóbora híbrida tipo "Tetsukabuto", empregando como fonte o sulfato de amônio, foi $251 \mathrm{~kg} \mathrm{ha}^{-1}$, para $\mathrm{Y}=3,0$, com produtividade de frutos de $17,15 \mathrm{t} \mathrm{ha}^{-1} \mathrm{e}$, empregando como fonte $\mathrm{o}$ nitrato de amônio, foi $238 \mathrm{~kg} \mathrm{ha}^{-1}$, para $\mathrm{Y}=9,2$, com produtividade de frutos de 17,07 $\mathrm{t} \mathrm{ha}^{-1}$. Mesmo diante do emprego de doses elevadas de $\mathrm{N}$, o acúmulo de nitrato em frutos de abóbora híbrida tipo "Tetsukabuto" alcançou nível pouco provável de ser considerado indesejável ao consumo humano.

\section{AGRADECIMENTOS}

Ao CNPq, pela concessão da bolsa de estudos de DS ao primeiro autor e de produtividade em pesquisa para $\mathrm{o}$ segundo, terceiro e quarto autores. À FAPEMIG, pelo apoio para realização do trabalho.

\section{REFERÊNCIAS}

ADDISCOTT TM; BENJAMIN N. 2004. Nitrate and human health. Soil and Use Manage 20: 98-104.

ALVAREZ VVH; NOVAIS RF; BARROS NF; CANTARUTTI RB; LOPES AS. 1999. Interpretação dos resultados das análises de solos. In: RIBEIRO AC; GUIMARES H; ALVAREZ V. VH. (eds). Recomendações para uso de corretivos e fertilizantes em Minas Gerais - $5^{a}$ Aproximação. Viçosa: CFSEMG. p. 25-32.

ANDRADE JUNIOR AS; DIAS NS; FIGUEIREDO JUNIOR LGM; RIBEIRO VQ; SAMPAIO DB. 2006. Produção e qualidade de frutos de melancia à aplicação de nitrogênio via fertirrigação. Revista Brasileira de Engenharia Agrícola e Ambiental 10: 836-841.

BENINNI ERY; TAKAHASHI HW; NEVES CSVJ; FONSECA ICB. 2002. Teor de nitrato em alface cultivada em sistemas hidropônico e convencional. Horticultura Brasileira 20: 183-186.

CASALI VWD. 1999. Moranga híbrida. In: RIBEIRO AC; GUIMARES H; ALVAREZ V. VH. (eds). Recomendações para uso de corretivos e fertilizantes em Minas Gerais - $5^{a}$ Aproximação. Viçosa: CFSEMG. p. 197.

CATALDO DA; HAROON M; SCHRADER LE; YOUNGS VL. 1975. Rapid colorimetric determination of nitrate in plant tissue by nitration of salicylic acid. Communication Soil Science and Plant Analysis 6: 71-80.

CEASA-MG - Central de Abastecimento do Estado de Minas Gerais. 2011, 10 de fevereiro. Preçose ofertas de produtos. Disponível em http://www. ceasaminas.com.br.

CHEN BM; WANG ZH; LI SX; WANG GX; SONG HX; WANG XN. 2004. Effects of nitrate supply on plant growth, nitrate accumulation, metabolic nitrate concentration and nitrate reductase activity in three leafy vegetables. Plant Science 167: 635-643.

CONAB - Companhia Nacional do Abastecimento. 2011, 10 de fevereiro. Preço dos insumos agropecuários. Disponível em http://www. conab.gov.br.

FERREIRA MMM; FERREIRA GB; FONTES PCR; DANTAS JP. 2006. Qualidade do tomate em função de doses de nitrogênio e da adubação orgânica em duas estações. Horticultura Brasileira 24: 141-145.

FILGUEIRA FAR. 2008. Novo manual de olericultura. 3. ed., Viçosa: UFV. 421p.

KROHN NG; MISSIO RF; ORTOLAN ML; BURIN A; STEINMACHER DA; LOPES MC. 2003. Teores de nitrato em folhas de alface em função do horário de coleta e do tipo de folha amostrada. Horticultura Brasileira 21: 216-219.

MANTOVANI JR; FERREIRA ME; CRUZ MCP. 2005. Produção de alface e acúmulo de nitrato em função da adubação nitrogenada. Horticultura Brasileira 23: 758-762.

MARSCHNER H. 1995. Mineral nutrition of higher plants. 2. ed. New York: Academic Press. 889p.

OLIVEIRA AP; OLIVEIRA ANP; ALVES AU; ALVES EU; SILVA DF; SANTOS RR; LEONARDO FAP. 2008. Rendimento de maxixeiro adubado com doses de nitrogênio. Horticultura Brasileira 26: 533-536.

PÔRTO ML; ALVES JC; SOUZA AP; ARAUJO RC; ARRUDA JA. 2008. Nitrate production and accumulation in lettuce as affected by mineral nitrogen supply and organic fertilization. Horticultura Brasileira 26: 227-230.

PÔRTO MLA; PUIATTI M; ALVES JCA; FONTES PCR; ARRUDA JA. 2012.
Produtividade e acúmulo de nitrato nos frutos de abobrinha em função da adubação nitrogenada. Bragantia 71: 190-195.

PUIATTI M; SILVA DJH. 2005. Abóboras e morangas. In: FONTES PCR (ed). Olericultura: teoria e prática. Viçosa: UFV. p. 279-297.

QUEIROGA RCF; PUIATTI M; FONTES PCR; CECON PR; FINGER FL. 2007. Influência de doses de nitrogênio na produtividade e qualidade do melão Cantalupensis sob ambiente protegido. Horticultura Brasileira 25: 550-556.

RAIJ BV. 2011. Fertilidade do solo e manejo de nutrientes. Piracicaba: IPNI. 420p.

SAEG. 2007. Sistema para Análises Estatísticas. Versão 9.1. Viçosa: Fundação Arthur Bernardes.

SANTAMARIA P. 2006. Nitrate in vegetables: toxicity, content, intake and EC regulation. Journal of the Science of Food and Agriculture 86: 10-17.

SANTOS WO; REBOUÇAS TNH; SANTOS LC; BENJAMIN CS; SANTOS TJ; PRADO NB; REBOUÇAS, KJ; NETO I. 2010. Nitrogênio no cultivo da abóbora híbrida Tetsukabuto no Sudoeste da Bahia. In: CONGRESSO BRASILEIRO DE OLERICULTURA, 50. Anais... Guarapari: ABH. (CD ROM).

SEDIYAMA MAN; VIDIGAL SM; SANTOS MR; MASCARENHAS MHT. 2009. Cultura da moranga híbrida ou abóbora Tetsukabuto. Belo Horizonte: EPAMIG. 58p. (EPAMIG. Boletim técnico, 92).

TURAN M; SEVIMLI F. 2005. Influence of different nitrogen sources and levels on ion content of cabbage (Brassica oleracea var. capitata). New Zealand Journal of Crop and Horticultural Science 33: 241-249.

TURAZI CMV; JUNQUEIRAAMR; OLIVEIRA SA; BORGO LA. 2006. Acúmulo de nitrato em alface em função da adubação, horário de colheita e tempo de armazenamento. Horticultura Brasileira 24: 65-70.

VIDIGAL SM; FACION CE; ARAÚJO JS. 2003. Avaliação de abóbora híbrida na região Norte de Minas Gerais. In: CONGRESSO BRASILEIRO DE OLERICULTURA, 43. Anais... Recife: ABH. (CD ROM).

VIDIGAL SM; PACHECO DD; FACION CE. Crescimento e acúmulo de nutrientes pela abóbora híbrida tipo Tetsukabuto. 2007. Horticultura Brasileira 25: 375-380.

WHO - World Health Organization. Evaluation of certain food additives and contaminants. (Fortyfourth report of the Joint FAO/WHO Expert Committee on Food Additives). Geneva: FAO/ WHO, 1995. 54p. (WHO Technical Report Series, 859). 